\title{
PROFESSOR CARLO EMERY
}

The eminent zoölogist Professor Carlo Emery, best known to entomologists for his extensive and valuable contributions on ants has died at the age of seventy-eight years. During his early career he pursued a course in general medicine, but in 1872 decided to specialize in ophthalmology. However, in 1878 he was appointed Professor of Zoölogy in the University of Cagliari where he remained for several years until 1881 when he went to the University of Bologna as Professor of Zoölogy a position which he filled for thirty-five years until his death.

Among his earlier works, prior to 1869 , are a text-book of general zoölogy and papers on fishes and molluses, but the long period of fifty-six years (1869-1925) was devoted almost entirely to a study of ants, upon which he published very extensively. These many contributions have won him lasting fame in the annals of entomology. 

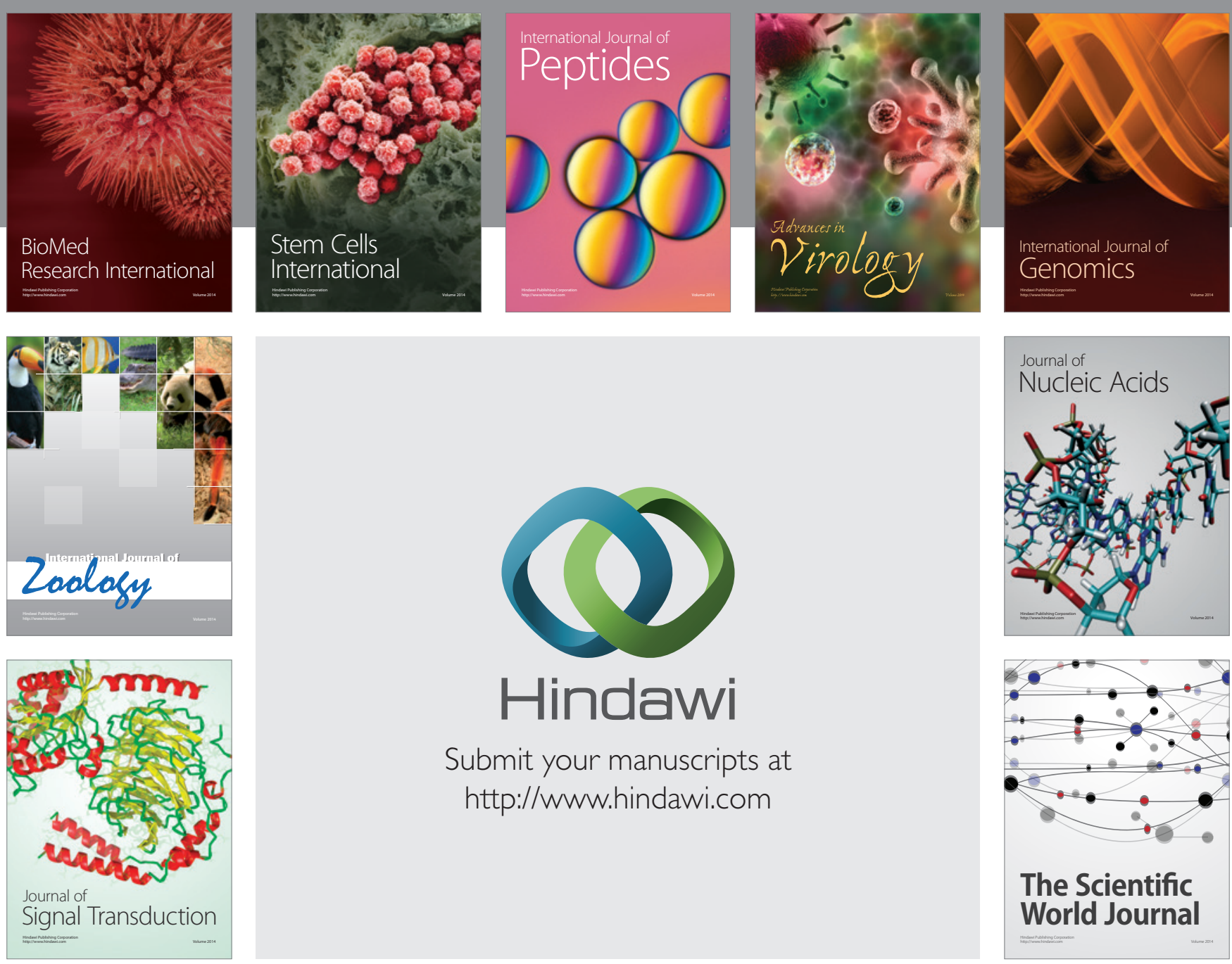

Submit your manuscripts at

http://www.hindawi.com
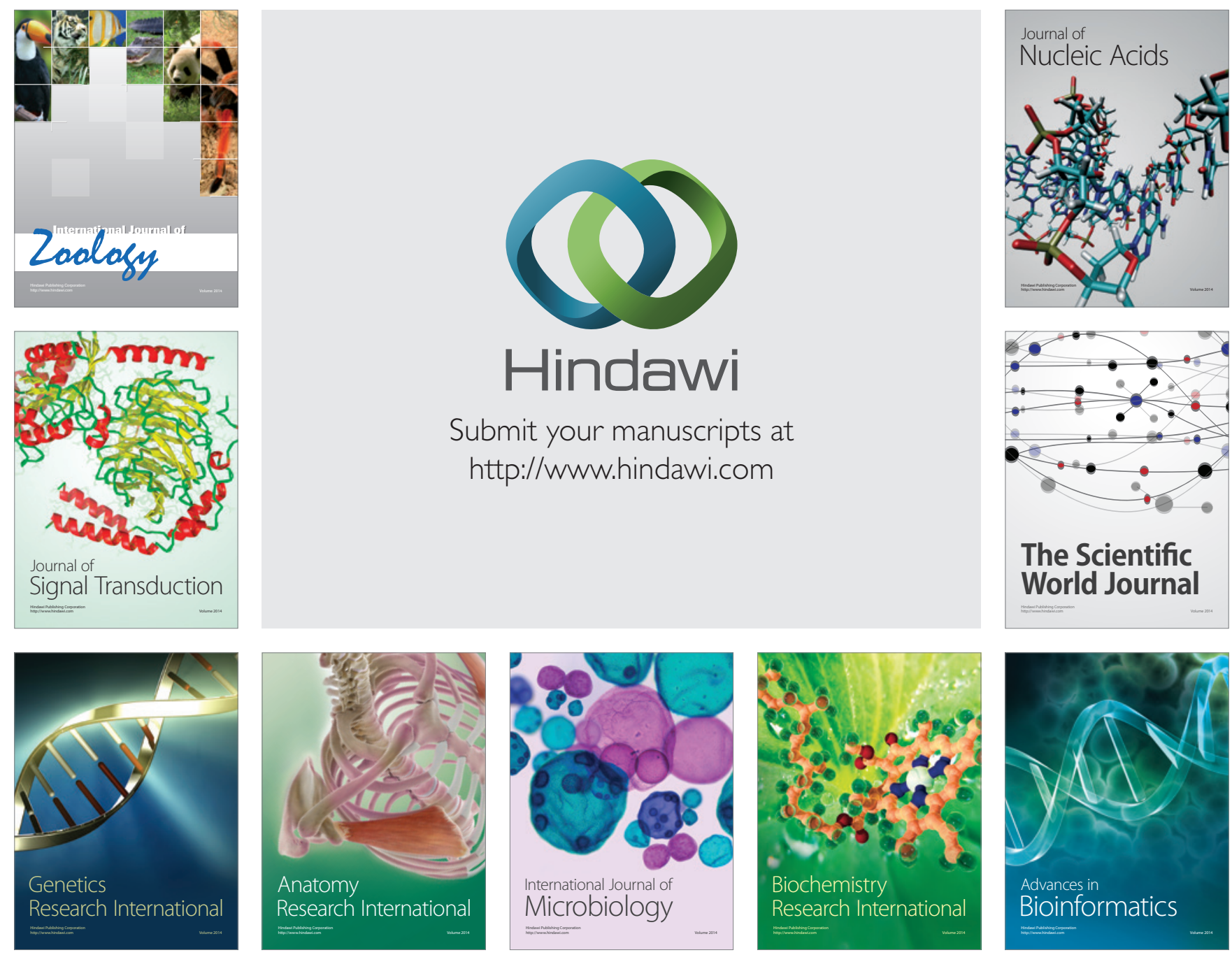

The Scientific World Journal
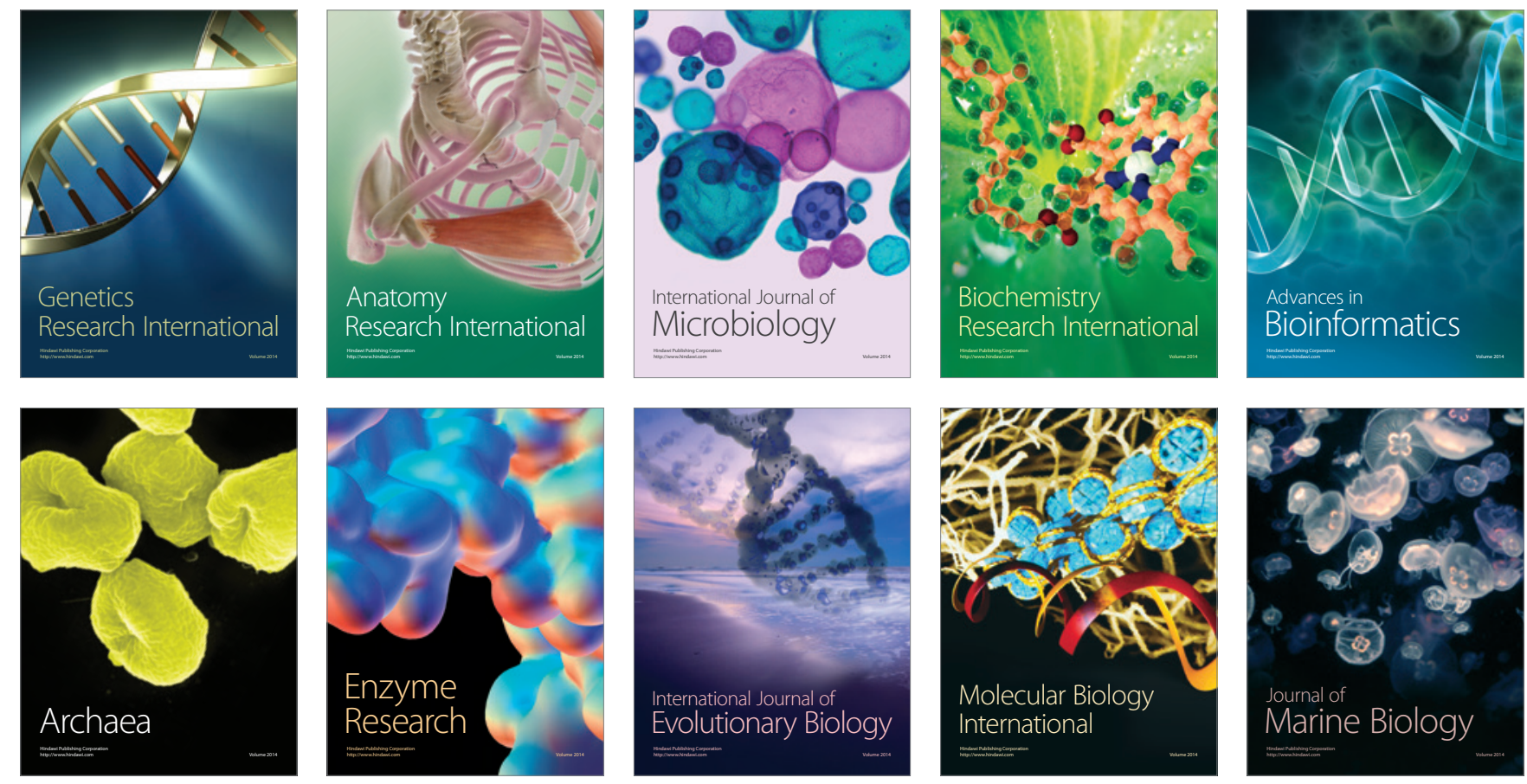